\title{
32. Heat pumps for decarbonizing buildings
}

\section{Dominique Bureau}

Buildings are responsible for more than a third of $\mathrm{CO}_{2}$ emissions in the European Union or North America. Heating systems and water heaters mainly contribute to direct and indirect emissions of the sector as long as they rely on fossil fuel combustion.

Several ways are available to cut down these emissions. They are more or less cost effective depending on the context. In the first place, energy efficiency of buildings is an important issue. Most of the building stock being inefficient, its renovation is a critical element of the clean energy transition in developed countries. However, while raising thermal standards is quite easy for new buildings, refurbishing existing buildings is more difficult. Then, another lever is the switch to fuels that emit less $\mathrm{CO}_{2}-$ coal or fuel oil to gas boilers, for example. With this approach, heat flows still follow the spontaneous direction of heat transfers, from the warmer to the colder environment.

Heat pumps move energy in the opposite direction. They draw heat from a colder spot than the building to be heated. The physical functioning is similar to that of a refrigerator. Their underlying principles were established in the nineteenth century by Nicolas Léonard Sadi Carnot and William Thomson (later Lord Kelvin). In particular, the second law of thermodynamics says that transferring energy in this direction needs additional external power. Hence, one may wonder why this is an energy-efficient solution for decarbonizing buildings.

The main reason is that most of the energy used in the heat pump cycle is coming from the external environment, air, water or ground. This energy is free, renewable, and does not contribute to global warming. Only the additional energy necessary to run the device involves direct and environmental costs.

Engineers measure the efficiency of heating systems by their coefficient of performance (COP), that is, the ratio between transferred energy and consumed energy for running electrically powered heat pumps. This ratio is equal to 1 for a conventional electrical resistance heater. It reaches 3-4 for heat pumps. Compared to a standard heating system using fossil fuel combustion, heat 
pumps thereby allow reductions in energy consumption in the range 65-75 per cent. Moreover, in countries where electricity is mostly decarbonized, they reduce $\mathrm{CO}_{2}$ emissions by $90-100$ per cent. Achieving such performances has required a lot of innovations, some of them quite recent.

If the principles of heat pumps are the same as those of refrigerators, the obstacles to be removed to obtain competitive systems are not small. Flows of energy are higher and the factors that affect the COP, such as weak temperature difference between sources, need optimization, the results of which depend on the context and resources availability.

Typically, tapping the atmosphere is simpler but higher performances are obtained with water or ground heat. Indeed, pioneering installations from the 1990s were using water. But access to lakes and rivers is limited, hence is generally not an option for the residential market.

Reversibility of (mostly air-air) heat pumps increases their value by providing two alternative services: air heating and air conditioning. In regions where both heat in winter and cooling in summer are necessary, reversible heat pumps can play a significant role in total final energy consumption. Thus, some further explanation on reversibility seems warranted here.

In both cases, heating and cooling, the heat pump thermodynamic cycle is the same: thanks to the working coolant fluid used, the source of heat is at a lower temperature than the sink of heat. The difference is that for a heating service, the heat source is outdoor and the heat sink indoor (place to be heated), while for a cooling service, the heat source is indoor (place to be cooled, inside the home as inside a refrigerator) and the heat sink outdoor. It is the same second law of thermodynamics behind both services, in terms of thermodynamic work to be supplied (mostly by electricity) compared to heat transfers from the hot source.

Since investment costs for heat pumps are higher than for conventional heating systems, improving efficiency and reducing capital expenditures remain the two key factors for enhanced deployment. As mentioned above, heat pump technology has been in constant evolution for 40 years, with many developments. They benefited from spillovers from technologies in air conditioning. Incremental innovation has also been recurrent in all segments of the heat pump industry, characterized by numerous international manufacturers and suppliers. Among the main players are: Daïkin, Mitsubishi Electric and Panasonic from Japan; Midea, Haier and Gree from China; Atlantic, NIBE, BDR Thermea, Ingersoll Rand, Viessmann, Stiebel Eltron, Vaillant from Europe; United Technologies-Carrier from the US, and so on. ${ }^{1}$ The average $\mathrm{COP}$, in standardized conditions, for aerothermal heat pumps on the French new residential market went from 3 in 1997 to 4.2 in 2015. ${ }^{2}$ 
Breakthroughs were obtained both at lab and firm levels:

- in the 1980s and 1990s: heating curve regulation, heat pump compressor with variable speed, electronic expansion valves;

- in the 2000s: compactness of heat exchangers, vapor injection;

- over the last decade: auto-diagnosis, real-time metering, better predictions, refrigerant fluids with lower global warming potential through greenhouse impact in (rarer) cases of leakage (hydrofluoroolefins, propane, $\mathrm{CO}_{2}$ and mixed), recovery of heat from garbage.

Expected in the next few years:

- $\quad$ self-settings and self-regulation for better use and increased performance;

- expanded skilled workforce for installation and maintenance, allowing for better availability of equipment and longer lifespan;

- coupling with heat storage associated with solar thermal or solar PV.

While air-source technologies have been historically dominant and ground-source technologies have been largely developed over the last decade, more recent developments are worth mentioning:

- hybrid heat pumps that include fossil fuel heating as a back-up in case of extreme low temperatures (that can lower heat pump performance);

- heat pumps dedicated to water heating uses (cleaning and cooking);

- higher temperature applications (temperature can reach $80^{\circ} \mathrm{C}$ in residential applications).

At the same time, total investment costs (equipment + installation) have been trimmed, by about 25 per cent since 2010 for air-source technologies. Installation costs count for 20 per cent for aerothermal pumps but for 30-50 per cent for geothermal ones. Efficiency and quality of service provided by the firms involved are thus crucial for the growth of the markets.

The dynamics of future deployment of these technologies will depend both on public policies and market efficiency. Public policies have been devised and implemented in many countries to reduce by wide margins the levels of energy consumption in buildings and to promote renewable sources of energy. Although not specifically targeted at heat pumps, all these policies have had a major impact on the market even when oil price decreases pushed in the opposite direction. One in two single-family houses has been equipped with a heat pump in France since 2014. In 2019, the market for renovation overtook the market for new buildings.

In Europe, the market has also been expanding over the last decade, from 734000 sales in 2009 to 1300000 in 2018 (21 countries). According to the European Heat Pump Association (EHPA), heat pumps sold in 2018 contrib- 
uted to 68228 jobs, $128 \mathrm{TWh}$ of renewable energy produced by the heat pump stock, $32.98 \mathrm{Mt}$ of greenhouse gas emissions avoided and $164 \mathrm{TWh}$ of final energy saved.

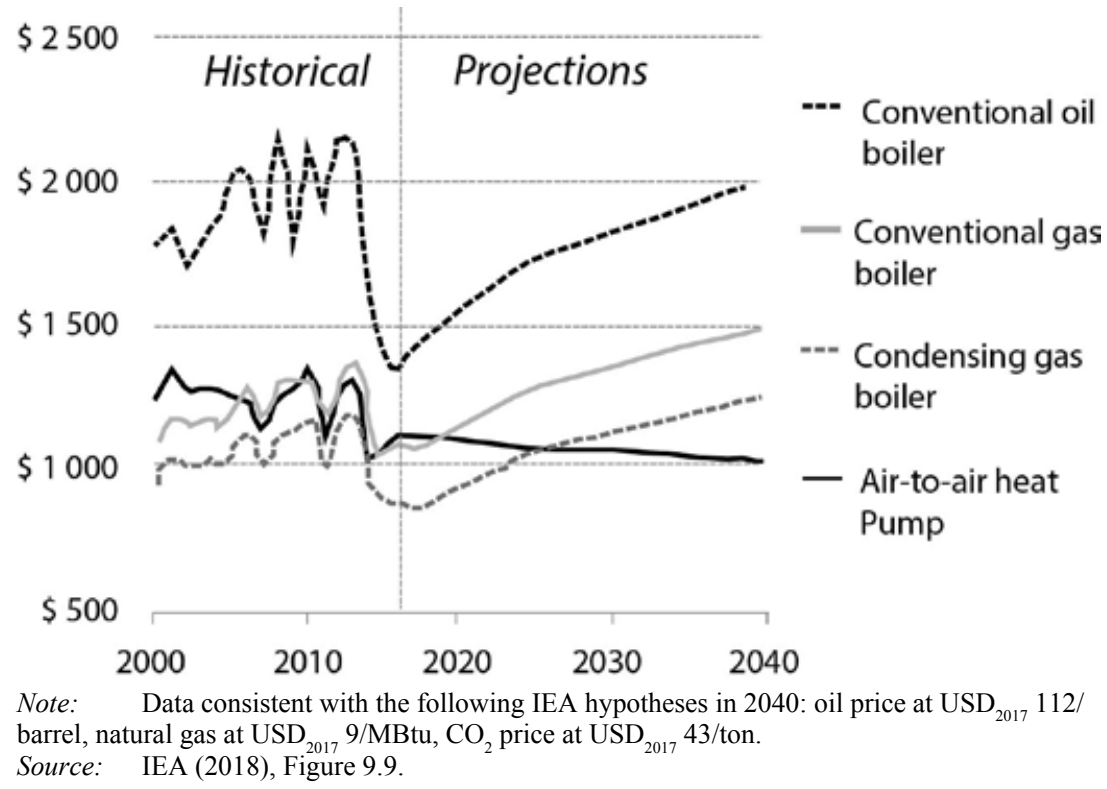

Figure 32.1 Annualized household heating costs (Europe): competitiveness of electric space heating

While heat pumps have existed for decades, recent history has witnessed significant technological innovations. And further performance improvements and cost decreases are possible to reduce the overall costs of the use of this type of equipment by households and increase their competitiveness (Figure 32.1). As a result, it is no wonder that heat pumps can become a major technology for heating (and cooling too, notably as global warming implies hotter summers) in future scenarios featuring climate policies, and a key enabler for building decarbonization, based on decarbonized electricity. In the International Energy Agency (IEA) "2 Degrees" scenario (2DS), the worldwide share of heat pump equipment in buildings in 2050 is thrice its share in 2014. In the "Beyond 2 Degrees" scenario (B2DS), this share reaches 43 per cent of all space and water heating equipment (Figure 32.2). 


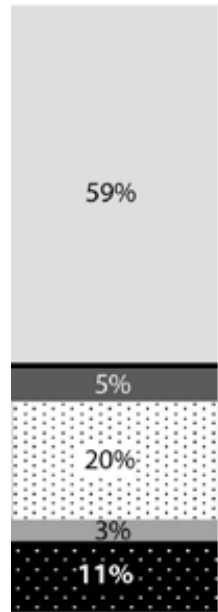

2014

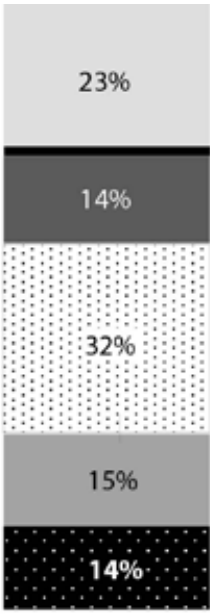

$20502 D S$

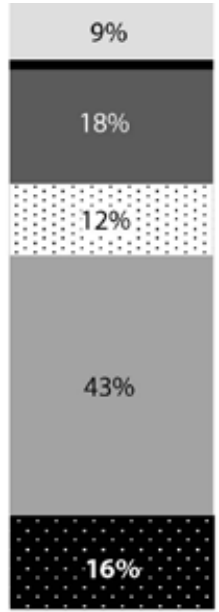

2050 B2DS

Note: Heating in buildings represents space and water heating; it excludes cooking and other end uses. Efficient gas technologies include gas condensing boilers, gas instantaneous equipment and gas heat pumps. Traditional use of solid biomass is not included.

Source: Author's figure based on IEA (2017)

Figure $32.2 \quad$ Evolution of space and water heating equipment shares in buildings in IEA Energy Technology Perspectives 2017 global scenarios

\section{NOTES}

1. In 2018, the global market size was USD58.6 billion with an estimated compound annual growth rate of 8.5 per cent from 2019 to 2025 . More than 75 per cent of the market is for residential applications; the remaining for both industrial and commercial applications (Grand View Research, 2020).

2. See Uniclima (2020), with similar results at the global level.

\section{REFERENCES}

European Heat Pump Association (EHPA) (2019), "Market data", accessed 17 August 2020 at www.ehpa.org/market-data/.

Grand View Research (2019), "Heat pump market size, share \& trends analysis report by technology", accessed August 17, 2020 at https://www.grandviewresearch.com/ industry-analysis/heat-pump-market.

International Energy Agency (IEA) (2017), Energy Technology Perspectives 2017, accessed 17 August 2020 at https://webstore.iea.org/download/direct/1058. All rights reserved. 
International Energy Agency (IEA) (2018), World Energy Outlook 2019, accessed 17 August 2020 at https://www.iea.org/reports/world-energy-outlook-2019. All rights reserved.

Uniclima (2020), "Bilan 2019 et perspectives 2020 du génie climatique”, press conference, Paris, 11-17 February, accessed 17 August 2020 at www.uniclima.fr/userfiles/ Doc/presse/2020_02_04_DP_UNICLIMA_RESULTATS.pdf. 